\title{
The effect of cobalt doping on the morphology and electrochemical performance of high-voltage spinel $\mathrm{LiNi}_{0.5} \mathrm{Mn}_{1.5} \mathrm{O}_{4}$ cathode material
}

Jing Mao ${ }^{\mathrm{a}, \mathrm{b}, \mathrm{c}}$, Mengze Ma ${ }^{\mathrm{a}, \mathrm{b}}$, Panpan Liu ${ }^{\mathrm{a}, \mathrm{b}}$, Junhua $\mathrm{Hu}^{\mathrm{a}}$, b Guosheng Shao ${ }^{\mathrm{a}, \mathrm{b}}$, Vince

$$
\text { Battaglia }^{\text {c }} \text { Kehua Dai }{ }^{\text {d, c, * }}, \text { Gao Liu }{ }^{\text {, } *}
$$

${ }^{\mathrm{a}}$ School of Materials Science and Engineering, Zhengzhou University, Zhengzhou 450002, China

${ }^{\mathrm{b}}$ International Joint Research Laboratory for Low-Carbon \& Environmental Materials of Henan Province, Zhengzhou University, Zhengzhou 450002, China

${ }^{c}$ Energy Storage and Distributed Resource Division, Energy Technologies Area, Lawrence Berkeley National Laboratory, Berkeley, CA 94720, USA

${ }^{\mathrm{d}}$ School of Materials and Metallurgy, Northeastern University, Shenyang 110004, China

*Corresponding Authors. Kehua Dai, Phone: +86(24) 83687731, Email: daikh@smm.neu.edu.cn.

Gao Liu, Phone: +1(510) 486-7207, Fax: +1(510) 486-7303, E-mail: gliu@ @bl.gov.

Abstract

To reveal the effect of Co-doping on the electrochemical performance of micro-sized $\mathrm{LiNi}_{0.5} \mathrm{Mn}_{1.5} \mathrm{O}_{4}$ (LNMO), undoped LNMO and Co-doped $\mathrm{LiCo}_{0.1} \mathrm{Ni}_{0.45} \mathrm{Mn}_{1.45} \mathrm{O}_{4}$ (LCoNMO) are synthesized via a PVP-combustion method and calcined at $1000{ }^{\circ} \mathrm{C}$ for 6h. SEM and XRD analyses suggest that Co-doping decreases the particle size and 
the $\mathrm{Li}_{2} \mathrm{Ni}_{1-z} \mathrm{O}_{2}$ impurity at the calcination temperature of $1000{ }^{\circ} \mathrm{C}$. LCoNMO has much better rate capability while its specific capacity at $\mathrm{C} / 5$ is $10 \%$ lower than that LNMO. At 15C rate, their specific capacities are closed, and the LCoNMO delivers 86.2\% capacity relative to $\mathrm{C} / 5$, and this value for $\mathrm{LNMO}$ is only $77.0 \%$. The $D_{\mathrm{Li}}+$ values determined by potential intermittent titration technique (PITT) test of LCoNMO are 1 2 times higher than that of LNMO in most $S O C$ region. The LCoNMO shows very excellent cycling performance, which is the best value compared with literatures. After 1000 cycles, the LCoNMO still delivers $94.1 \%$ capacity. Moreover, its coulombic efficiency and energy efficiency keep at $99.84 \%$ and over $97.3 \%$ during $1 \mathrm{C}$ cycling, respectively.

Keywords: high-voltage spinel; lithium nickel manganese oxide; Lithium chemical diffusion coefficient; cycling performance; rate performance.

\section{Introduction}

Next generation lithium-ion batteries for EV, HEV, energy storage, etc. request high energy density, high operation voltage, high rate capability and cycling stability cathode materials. $\mathrm{LiMn}_{1.5} \mathrm{Ni}_{0.5} \mathrm{O}_{4}$ (LNMO) with spinel structure is a promising candidate for its high working voltage of $\sim 4.7 \mathrm{~V}$ and capacity of $\sim 130 \mathrm{mAh} \mathrm{g}^{-1}$ [1-7]. The main concern about this material is the capacity fading in full cells due to electrolyte decomposition and concurrent degradative reactions at electrode/electrolyte interfaces [5, 8-10]. Moreover, comparing to spinel LiMn2O4, LNMO shows lower rate performance and needs to be improved by doping. 
Doping is one of the most popular ways to improve the cycling performance and/or rate performance of LNMO [11, 12]. Among the reported doping cations and anions [11, 13-34], Co-doping shows great improvement on rate capability and cycling stability of LNMO [2, 16, 19, 21, 28]. We previously reported micro-sized LNMO synthesized via a PVP-combustion method with excellent rate capability and cycling stability [35]. Thus, further improvement of rate and cycling performance could be anticipated by combining Co-doping and PVP-combustion method.

In this paper, undoped $\mathrm{LiNi}_{0.5} \mathrm{Mn}_{1.5} \mathrm{O}_{4} \quad$ (LNMO) and Co-doped $\mathrm{LiCo}_{0.1} \mathrm{Ni}_{0.45} \mathrm{Mn}_{1.45} \mathrm{O}_{4}$ (LCoNMO) are synthesized via PVP-combustion method and calcined at $1000{ }^{\circ} \mathrm{C}$ for $6 \mathrm{~h}$. The improved rate capability and the very excellent cycling stability of LCoNMO are exhibited.

\section{Experimental}

\subsection{Synthesis procedure}

The undoped $\mathrm{LiNi}_{0.5} \mathrm{Mn}_{1.5} \mathrm{O}_{4}$ (LNMO) and Co-doped $\mathrm{LiCo}_{0.1} \mathrm{Ni}_{0.45} \mathrm{Mn}_{1.45} \mathrm{O}_{4}$ (LCoNMO) were prepared by polyvinylpyrrolidone (PVP)-combustion method. In detail, stoichiometric LiOAc. $2 \mathrm{H}_{2} \mathrm{O}, \quad \mathrm{Ni}\left(\mathrm{NO}_{3}\right)_{2} \cdot 6 \mathrm{H}_{2} \mathrm{O}, \quad \mathrm{Mn}(\mathrm{OAc})_{2} \cdot 4 \mathrm{H}_{2} \mathrm{O}$, $\mathrm{Co}(\mathrm{OAc})_{2} \cdot 4 \mathrm{H}_{2} \mathrm{O}$, and PVP (the molar ratio of PVP monomer to total metal ions was 2 : 1) were dissolved in deionized water and $\mathrm{pH}=3$ was achieved by adding $1: 1 \mathrm{HNO}_{3}$. The mixture was stirred at $120^{\circ} \mathrm{C}$ to obtain a dry gel, which was ignited on a hot plate to induce a combustion process that lasted for several minutes. The resulting precursor was preheated at $450{ }^{\circ} \mathrm{C}$ for $3 \mathrm{~h}$ and then calcined at $1000{ }^{\circ} \mathrm{C}$ for $6 \mathrm{~h}$ with the heating rate of $5{ }^{\circ} \mathrm{C} \min ^{-1}$. After heat treatment, the oven was switched off and the sample was cooled down naturally. 


\subsection{Morphology and structure characterization}

The analysis of the phase purity and the structural characterization were made by X-ray powder diffraction (XRD) using a Bruker D2 PHASER diffractometer equipped with $\mathrm{Cu} \mathrm{K} \alpha$ radiation that was operated over a $2 \theta$ range of $10 \sim 70^{\circ}$ in a continuous scan mode with a step size of $0.004^{\circ}$. The morphology was examined using a JEOL 7500F scanning electron microscope (SEM).

\subsection{Electrochemical tests}

The cathode was prepared by mixing $82 \mathrm{wt} . \%$ active material, $10 \mathrm{wt} . \%$ acetylene black (AB) and 8 wt.\% polyvinylidene fluoride (PVdF) binder in N-methylpyrrolidone (NMP) to form a slurry. The slurry was doctor-bladed onto aluminum foil, dried at $60{ }^{\circ} \mathrm{C}$, and then punched into electrode discs with a diameter of $12.7 \mathrm{~mm}$. The prepared electrodes were dried at $130{ }^{\circ} \mathrm{C}$ for $12 \mathrm{~h}$ in a vacuum oven and show typically an active material loading of about $5 \mathrm{mg}$. The electrochemical cells were fabricated with the LNMO cathode, lithium foil anode, $1 \mathrm{~mol} \mathrm{~L}^{-1} \mathrm{LiPF}_{6}$ in 1:1 EC/DEC as electrolyte, and Celgard 2400 as separator in an argon-filled glove box. Electrochemical performances were evaluated using CR2325 coin cells. Galvanostatic charge-discharge tests were performed using Maccor 4000. The potential intermittent titration technique (PITT) test were conducted using Bio-Logic VMP-3 multichannel electrochemical analyzer.

\section{Results and discussion}

Fig. 1 shows the SEM images of LNMO and LCoNMO. The shapes of particles for LNMO and LCoNMO have not much difference while small and big particles are less 
for LCoNMO. The particle size distributions are counted from 200 particles in lower magnification SEM images and are shown in Fig. 2 and Table 1. It can be seen that the mean particle size becomes smaller and the particles whose sizes are between 4 and $5 \mu \mathrm{m}$ are less with Co-doping. The more centralized particle size distribution and smaller standard deviation value for LCoNMO indicate more uniform particle sizes.

Fig. 3 shows the XRD patterns of LNMO and LCoNMO. All diffraction peaks can be indexed as a cubic spinel structure and $F d \overline{3} m$ space group, and all of the peaks are narrow and sharp, indicating good crystallinity. The pattern of LNMO shows a weak peak related to $\mathrm{Li}_{z} \mathrm{Ni}_{1-z} \mathrm{O}_{2}$ at $2 \theta \approx 43.7^{\circ}$ [20] while this peak for LCoNMO is much weaker. The suppression of $\mathrm{Li}_{z} \mathrm{Ni}_{1-z} \mathrm{O}_{2}$ in high-voltage LNMO by Co-doping agrees with previous report [28].

Fig. 4a displays the charge and discharge profiles of LNMO and LCoNMO at C/5 rate in the $5^{\text {th }}$ cycle. The charge capacity of LNMO and LCoNMO are 136.4 and $120.8 \mathrm{mAh} \mathrm{g}^{-1}$, respectively, and the discharge capacity of LNMO and LCoNMO are 130.3 and $117.3 \mathrm{mAh} \mathrm{g}^{-1}$, respectively. The $10 \%$ capacity loss for the LCoNMO is due to the $10 \%$ decrease of $\mathrm{Ni}$ content relative to the $\mathrm{LNMO}$ and the $\mathrm{Co}^{3+} / \mathrm{Co}^{4+}$ redox is not active below $5 \mathrm{~V}$ in this material $[36,37]$. The coulombic efficiency of LNMO and LCoNMO are $95.5 \%$ and $97.1 \%$ respectively. The higher coulombic efficiency for LCoNMO indicates less side reactions. The charge and discharge profiles of LNMO and LCoNMO both show three plateaus which suggest $F d \overline{3} m$ space group [38-41]. It is well known that the $4.6 \mathrm{~V}$ and $4.7 \mathrm{~V}$ plateaus are related to $\mathrm{Ni}^{2+} / \mathrm{Ni}^{3+}$ and $\mathrm{Ni}^{3+} / \mathrm{Ni}^{4+}$ redox, and the $4.0 \mathrm{~V}$ plateau is caused by $\mathrm{Mn}^{3+} / \mathrm{Mn}^{4+}[27]$. The $4.7 \mathrm{~V}$ plateau 
is higher and the $4.6 \mathrm{~V}$ plateau is lower for the LCoNMO than that for the LNMO. The voltage of the $4.7 \mathrm{~V}$ peaks in the $d Q / d V$ curves (Fig. 4b) for LCoNMO increase by $19 \mathrm{mV}$ at charge side and $24 \mathrm{mv}$ at discharge side relative to LNMO. The voltage of the $4.6 \mathrm{~V}$ peaks for LCoNMO decrease by $15 \mathrm{mV}$ at charge side and $19 \mathrm{mv}$ at discharge side relative to LNMO. The intensity of the $4.6 \mathrm{~V}$ and $4.7 \mathrm{~V}$ peaks for LCoNMO is weaker than that for LNMO while that of the $4.0 \mathrm{~V}$ peak is a little stronger. The higher $4 \mathrm{~V}$ region for Co-doped $\mathrm{LNMO}$ was also found in previous reports [28, 42]. This suggests more $\mathrm{Mn}^{3+}$ which can be ascribed to oxygen loss [43]. Li et al. [42] considered that the higher loss of oxygen relates to the substitution of cobalt for $\mathrm{Ni}$ and $\mathrm{Mn}$, which results in a significant change in the nearest neighbor oxygen environment.

To test the rate capability of LNMO and LCoNMO, the cells are charged and discharged at $\mathrm{C} / 5$ for 5 cycles, then they are charged at $1 \mathrm{C}$ and discharged at $1 \mathrm{C}, 5$ $\mathrm{C}, 10 \mathrm{C}$, and $15 \mathrm{C}$ for 5 cycles each followed by $1 \mathrm{C}$ cycling. The specific capacities at different C-rates are shown in Fig. 5a. Although the specific discharge capacities of LCoNMO are lower than that of LNMO, the rate capability of LCoNMO is much better than that of LNMO. At $15 \mathrm{C}$ rate, their specific capacities are closed, and the LCoNMO delivers $86.2 \%$ capacity relative to C/5, while this value for LNMO is only 77.0\% (Table 1). In previous discussion, the LCoNMO shows smaller particle sizes, so it needs to be determined that which factor results in the better rate performance, lower particle size, higher solid diffusion coefficient, or both. For this question, the lithium chemical diffusion coefficient is determined by potential intermittent titration 
technique (PITT). In the PITT experiments, a very small potential step size $(10 \mathrm{mV})$ and a low enough cutoff current $(\mathrm{C} / 50)$ were adopted to ensure that the equilibrium states were achieved at every potential step. Then the lithium chemical diffusion coefficient, $D_{\mathrm{Li}}+$, can be calculated from the slope of the linear region in the $\ln I(t) v s$. $t$ plot, as defined in Equation (1) [44, 45]

$$
D_{\mathrm{Li}^{+}}=-\frac{d \ln (I)}{d t} \frac{4 L^{2}}{\pi^{2}}
$$

where $I$ is the current in the potential step and $L$ is the diameter of a spherical particle. In this work, the quadratic mean of particle size is used as the $L$ value. The values of $D_{\mathrm{Li}}+$ measured from PITT are compared in Fig. 5b. The lithium diffusion coefficient values are between $5 \times 10^{-12}$ and $6 \times 10^{-10} \mathrm{~cm}^{2} \mathrm{~s}^{-1}$ for LNMO and $8 \times 10^{-12}$ and $7 \times 10^{-10}$ $\mathrm{cm}^{2} \mathrm{~s}^{-1}$ for LCoNMO. Three diffusion minima are observed which are corresponding to the three plateaus for LNMO. The $D_{\mathrm{Li}}+$ values of LCoNMO are 1 2 times higher than that of LNMO in most SOC region. Considering that the particle size decrease for Co-doping is small, the improved diffusion coefficient is one of main reasons of the rate capability improvement.

The LNMO and LCoNMO are cycled at $1 \mathrm{C}$ after rate tests. The cycling performance is displayed in Fig. 6a and the discharge profiles of LNMO at different cycles are shown in Fig. 6b. The LNMO shows quick capacity fading after $\sim 430$ cycles while the LCoNMO is cycled stably in 1000 cycles. To exclude occasionality, Several parallel tests of the undoped LNMO indicate the results are repeatable.. The fast fading after stable cycling may be caused by the continuous side reactions between LNMO and electrolyte. When the products of the side reactions accumulate 
to a certain degree, the reactions may accelerate to damage the electrolyte and anode, and cause avalanche capacity fading. The percent capacity fading per cycle for LNMO in $1-400$ cycles is $0.02 \%$, which is a rather good value. However, the value for LCoNMO is even much lower at $0.0059 \%$. After 1000 cycles, the LCoNMO still delivers $94.1 \%$ capacity. Table 2 shows the LCoNMO in this paper has the best cycling performance compared with the values in literatures. Moreover, it can be seen in Fig. 6b, the voltage plateaus for LCoNMO keep stable, only have a little drop after 1000 cycles.

Coulombic efficiency $(C E)$ of electrode materials is important for good cycling performance of full cells. Fig. 6c exhibits the $C E$ of LNMO and LCoNMO during 1C cycling. The $C E$ of LCoNMO reaches stable after around 200 cycles and then keeps at $99.84 \%$ up to 1000 cycles. The $C E$ of LNMO drops after around 200 cycles and becomes very unstable after around 430 cycles. These results suggest that Co-doping suppresses side reactions during cycling. Energy efficiency $(E E)$ of electrode materials is also important for cathode materials and is discussed not much in literatures. Fig. 6d shows the $E E$ of LNMO and LCoNMO during $1 \mathrm{C}$ cycling. The $E E$ of LCoNMO keeps stable and is still $97.3 \%$ at the 1000th cycle. Nevertheless, that of LNMO drops more quickly and drops severely after around 450 cycles. The high $E E$ cycling stability and high capacity cycling stability for LCoNMO ensure high energy density during cycling.

\section{Conclusions}

The undoped $\mathrm{LiNi}_{0.5} \mathrm{Mn}_{1.5} \mathrm{O}_{4}$ (LNMO) and Co-doped $\mathrm{LiCo}_{0.1} \mathrm{Ni}_{0.45} \mathrm{Mn}_{1.45} \mathrm{O}_{4}$ 
(LCoNMO) are synthesized via PVP-combustion method and calcined at $1000{ }^{\circ} \mathrm{C}$ for 6h. Co-doping decreases the particle size and weakens the $\mathrm{Li}_{z} \mathrm{Ni}_{1-z} \mathrm{O}_{2}$ impurity at the calcination temperature of $1000{ }^{\circ} \mathrm{C}$. LCoNMO has much better rate capability while its specific capacity at $\mathrm{C} / 5$ is $10 \%$ lower than LNMO. At $15 \mathrm{C}$ rate, their specific capacity are closed, and the LCoNMO delivers $86.2 \%$ capacity relative to $\mathrm{C} / 5$, while this value for LNMO is only $77.0 \%$. The $D_{\mathrm{Li}}+$ values of LCoNMO are 1 2 times higher than that of LNMO in most SOC region. Considering the particle size decrease for Co-doping is small, the improved diffusion coefficient is one of main reasons of the rate capability improvement. The LCoNMO also shows much improved cycling performance which is the best value compared with literatures. After 1000 cycles, the LCoNMO still delivers $94.1 \%$ capacity. Moreover, its coulombic efficiency and energy efficiency keep at $99.84 \%$ and over $97.3 \%$ during 1C cycling, respectively.

\section{Acknowledgements}

This work was supported by the National Natural Science Foundation of China (51204038, U1504521) and the Fundamental Research Funds for the Central Universities of China (N110802002, L1502004). This work was also supported by the Assistant Secretary for Energy Efficiency, Vehicle Technologies Office of the U.S. Department of Energy, under the Advanced Battery Materials Research (BMR) Program and Applied Battery Research (ABR) Program under contract No. DE-AC02-05CH11231.

\section{References}

[1] A. Manthiram, K. Chemelewski, E.-S. Lee, Energy Environ. Sci., 7 (2014) 
1339-1350.

[2] J. Hassoun, K.-S. Lee, Y.-K. Sun, B. Scrosati, J. Am. Chem. Soc., 133 (2011) 3139-3143.

[3] R. Santhanam, B. Rambabu, J. Power Sources, 195 (2010) 5442-5451.

[4] M. Hu, X. Pang, Z. Zhou, J. Power Sources, 237 (2013) 229-242.

[5] J.H. Kim, N.P. Pieczonka, L. Yang, Chemphyschem, 15 (2014) 1940-1954.

[6] K. Amine, H. Tukamoto, H. Yasuda, Y. Fujita, J. Power Sources, 68 (1997) 604-608.

[7] Q.M. Zhong, A. Bonakdarpour, M.J. Zhang, Y. Gao, J.R. Dahn, J. Electrochem. Soc., 144 (1997) 205-213.

[8] X. Wu, X. Li, Z. Wang, H. Guo, P. Yue, Ionics, 19 (2013) 379-383.

[9] J.-H. Kim, N.P. Pieczonka, Z. Li, Y. Wu, S. Harris, B.R. Powell, Electrochim. Acta, 90 (2013) 556-562.

[10] D. Aurbach, B. Markovsky, Y. Talyossef, G. Salitra, H.-J. Kim, S. Choi, J. Power Sources, 162 (2006) 780-789.

[11] S.H. Oh, S.H. Jeon, W.I. Cho, C.S. Kim, B.W. Cho, J. Alloy. Compd., 452 (2008) 389-396.

[12] T.F. Yi, Y. Xie, M.F. Ye, L.J. Jiang, R.S. Zhu, Y.R. Zhu, Ionics, 17 (2011) 383-389.

[13] T. Arunkumar, A. Manthiram, Electrochim. Acta, 50 (2005) 5568-5572.

[14] S.B. Park, W.S. Eom, W.I. Cho, H. Jang, J. Power Sources, 159 (2006) 679-684.

[15] M. Aklalouch, J.M. Amarilla, R.M. Rojas, I. Saadoune, J.M. Rojo, J. Power 
Sources, 185 (2008) 501-511.

[16] A. Ito, D. Li, Y. Lee, K. Kobayakawa, Y. Sato, J. Power Sources, 185 (2008) $1429-1433$.

[17] M. Aklalouch, R.M. Rojas, J.M. Rojo, I. Saadoune, J.M. Amarilla, Electrochim. Acta, 54 (2009) 7542-7550.

[18] J. Liu, A. Manthiram, J. Electrochem. Soc., 156 (2009) A66-a72.

[19] J. Liu, A. Manthiram, Chem. Mater., 21 (2009) 1695-1707.

[20] S.H. Oh, K.Y. Chung, S.H. Jeon, C.S. Kim, W.I. Cho, B.W. Cho, J. Alloy. Compd., 469 (2009) 244-250.

[21] S.W. Oh, S.-T. Myung, H.B. Kang, Y.-K. Sun, J. Power Sources, 189 (2009) $752-756$.

[22] H.L. Wang, H. Xia, M.O. Lai, L. Lu, Electrochem. Commun., 11 (2009) $1539-1542$.

[23] M. Aklalouch, J.M. Amarilla, R.M. Rojas, I. Saadoune, J.M. Rojo, Electrochem. Commun., 12 (2010) 548-552.

[24] D.Q. Liu, Y.H. Lu, J.B. Goodenough, J. Electrochem. Soc., 157 (2010) A1269-a1273.

[25] L. Lui, H.L. Wang, T.A. Tan, P. Yang, M.O. Lai, J. Phys. Chem. C, 115 (2011) 6102-6110.

[26] D. Liu, J. Hamel-Paquet, J. Trottier, F. Barray, V. Gariépy, P. Hovington, A. Guerfi, A. Mauger, C. Julien, J. Goodenough, J. Power Sources, 217 (2012) 400-406.

[27] D.W. Shin, C.A. Bridges, A. Huq, M.P. Paranthaman, A. Manthiram, Chem. 
Mater., 24 (2012) 3720-3731.

[28] G. Zhong, Y. Wang, Y. Yu, C. Chen, J. Power Sources, 205 (2012) 385-393.

[29] N. Kiziltas-Yavuz, A. Bhaskar, D. Dixon, M. Yavuz, K. Nikolowski, L. Lu, R.-A.

Eichel, H. Ehrenberg, J. Power Sources, 267 (2014) 533-541.

[30] M. Mo, K. Hui, X. Hong, J. Guo, C. Ye, A. Li, N. Hu, Z. Huang, J. Jiang, J. Liang, Appl. Surf. Sci., 290 (2014) 412-418.

[31] J. Wang, W. Lin, B. Wu, J. Zhao, Electrochim. Acta, 145 (2014) 245-253.

[32] R. Younesi, S. Malmgren, K. Edström, S. Tan, J. Solid State Electr., 18 (2014) 2157-2166.

[33] X.X. Xu, J. Yang, Y.Q. Wang, Y.N. NuLi, J.L. Wang, J. Power Sources, 174 (2007) 1113-1116.

[34] Y.-K. Sun, S.W. Oh, C.S. Yoon, H.J. Bang, J. Prakash, J. Power Sources, 161 (2006) 19-26.

[35] J. Mao, K. Dai, Y. Zhai, Electrochim. Acta, 63 (2012) 381-390.

[36] H. Kawai, M. Nagata, H. Tukamoto, A.R. Westa, Electrochem. Solid-State Lett., 1 (1998) 212-214.

[37] H. Kawai, M. Nagata, H. Kageyama, H. Tukamoto, A.R. West, Electrochim. Acta, 45 (1999) 315-327.

[38] S. Ivanova, E. Zhecheva, R. Stoyanova, D. Nihtianova, S. Wegner, P. Tzvetkova, S. Simova, J. Phys. Chem. C, 115 (2011) 25170-25182.

[39] J. Cabana, M. Casas-Cabanas, F.O. Omenya, N.A. Chernova, D. Zeng, M.S. Whittingham, C.P. Grey, Chem. Mater., 24 (2012) 2952-2964. 
[40] N. Amdouni, K. Zaghib, F. Gendron, A. Mauger, C. Julien, Ionics, 12 (2006) 117-126.

[41] L. Wang, H. Li, X. Huang, E. Baudrin, Solid State Ionics, 193 (2011) 32-38.

[42] D. Li, A. Ito, K. Kobayakawa, H. Noguchi, Y. Sato, J. Power Sources, 161 (2006) $1241-1246$.

[43] J.H. Kim, S.T. Myung, C.S. Yoon, S.G. Kang, Y.K. Sun, Chem. Mater., 16 (2004) 906-914.

[44] C.J. Wen, B.A. Boukamp, R.A. Huggins, W. Weppner, J. Electrochem. Soc., 126 (1979) 2258-2266.

[45] B. Hai, A.K. Shukla, H. Duncan, G. Chen, J. Mater. Chem. A, 1 (2013) 759-769. 
Table 1. The particle size and electrochemical performance data of LNMO and LCONMO.

\begin{tabular}{|c|c|c|c|c|c|c|c|c|}
\hline \multirow{2}{*}{$\begin{array}{l}\text { Sample's } \\
\text { name }\end{array}$} & \multirow{2}{*}{$\begin{array}{c}\text { Mean } \\
\text { particle } \\
\text { size }(\mu \mathrm{m})\end{array}$} & \multirow{2}{*}{$\begin{array}{c}\text { Particle size } \\
\text { standard } \\
\text { deviation }\end{array}$} & \multirow{2}{*}{$\begin{array}{c}\text { Discharge } \\
\text { capacity at } \\
\mathrm{C} / 5\left(\mathrm{mAh} \mathrm{g}^{-1}\right)\end{array}$} & \multicolumn{4}{|c|}{$\begin{array}{l}\text { Capacity ratio related to } \\
\text { capacity at } \mathrm{C} / 5(\%)\end{array}$} & \multirow{2}{*}{$\begin{array}{c}\text { Capacity fading } \\
\text { per cycle at } 1 \mathrm{C}^{*} \\
(\%)\end{array}$} \\
\hline & & & & $1 \mathrm{C}$ & $5 \mathrm{C}$ & $10 \mathrm{C}$ & $15 \mathrm{C}$ & \\
\hline LNMO & 2.97 & 0.97 & 130.3 & 95.8 & 87.0 & 81.8 & 77.0 & 0.020 \\
\hline LCoNMO & 2.69 & 0.93 & 117.3 & 96.6 & 92.3 & 88.7 & 86.2 & 0.0059 \\
\hline
\end{tabular}

Table 2. Comparation of the electrochemical performance for the LCoNMO in this paper and in literatures.

\begin{tabular}{lllll} 
& & \multicolumn{2}{c}{ Cycling performance } & \\
\cline { 3 - 4 } Refs & Chemical formula & C-rate & $\begin{array}{l}\% \text { capacity } \\
\text { degradation } \\
\text { per cycle }\end{array}$ & $\begin{array}{l}\text { Coulombic } \\
\text { efficiency }\end{array}$ \\
\hline This work & $\mathrm{LiCo}_{0.10} \mathrm{Ni}_{0.45} \mathrm{Mn}_{1.45} \mathrm{O}_{4}$ & $1 \mathrm{C}$ & $0.0059 \%$ & $99.8 \% @ 1 \mathrm{C}$ \\
\hline 2 & $\mathrm{LiCo}_{0.10} \mathrm{Ni}_{0.45} \mathrm{Mn}_{1.45} \mathrm{O}_{4}$ & $0.5 \mathrm{C}$ & $0.023 \%$ & \\
\hline 19 & $\mathrm{LiCo}_{0.16} \mathrm{Ni}_{0.42} \mathrm{Mn}_{1.42} \mathrm{O}_{4}$ & $\mathrm{C} / 6$ & $0.14 \%$ & \\
\hline 21 & $\mathrm{LiCo}_{0.05} \mathrm{Ni}_{0.5} \mathrm{Mn}_{1.45} \mathrm{O}_{4}$ & $0.5 \mathrm{C}$ & $0.06 \%$ & \\
\hline 28 & $\mathrm{LiCo}_{0.10} \mathrm{Ni}_{0.45} \mathrm{Mn}_{1.45} \mathrm{O}_{4}$ & $1 \mathrm{C}$ & $0.0082 \%$ & \\
\hline
\end{tabular}




\section{Fig captions}

Fig. 1. The SEM images of LNMO and LCoNMO.

Fig. 2. The Particle size distributions of LNMO and LCoNMO.

Fig. 3. The XRD patterns of LNMO and LCoNMO.

Fig. 4. (a) The charge-discharge profiles and (b) the $d Q / d V$ profiles of LNMO and LCoNMO. The rate is $\mathrm{C} / 5$.

Fig. 5. (a) The specific capacity at different C-rates and (b) chemical diffusion coefficient at different SOC of LNMO and LCoNMO.

Fig. 6. (a) The cycling performance of LNMO and LCoNMO. (b) The discharge profiles of LCoNMO at different cycles. (c) The coulombic efficiency and (d) energy efficiency of LNMO and LCoNMO at different cycles. The discharge rate is $1 \mathrm{C}$. 
Figures

Figure 1
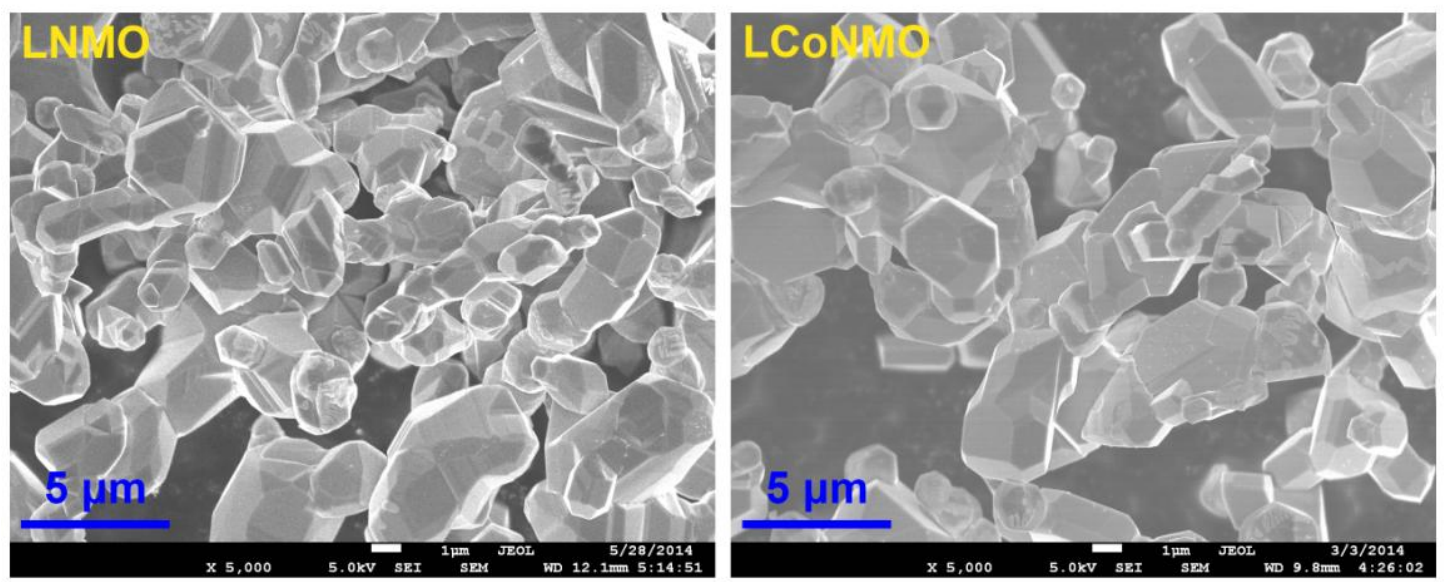

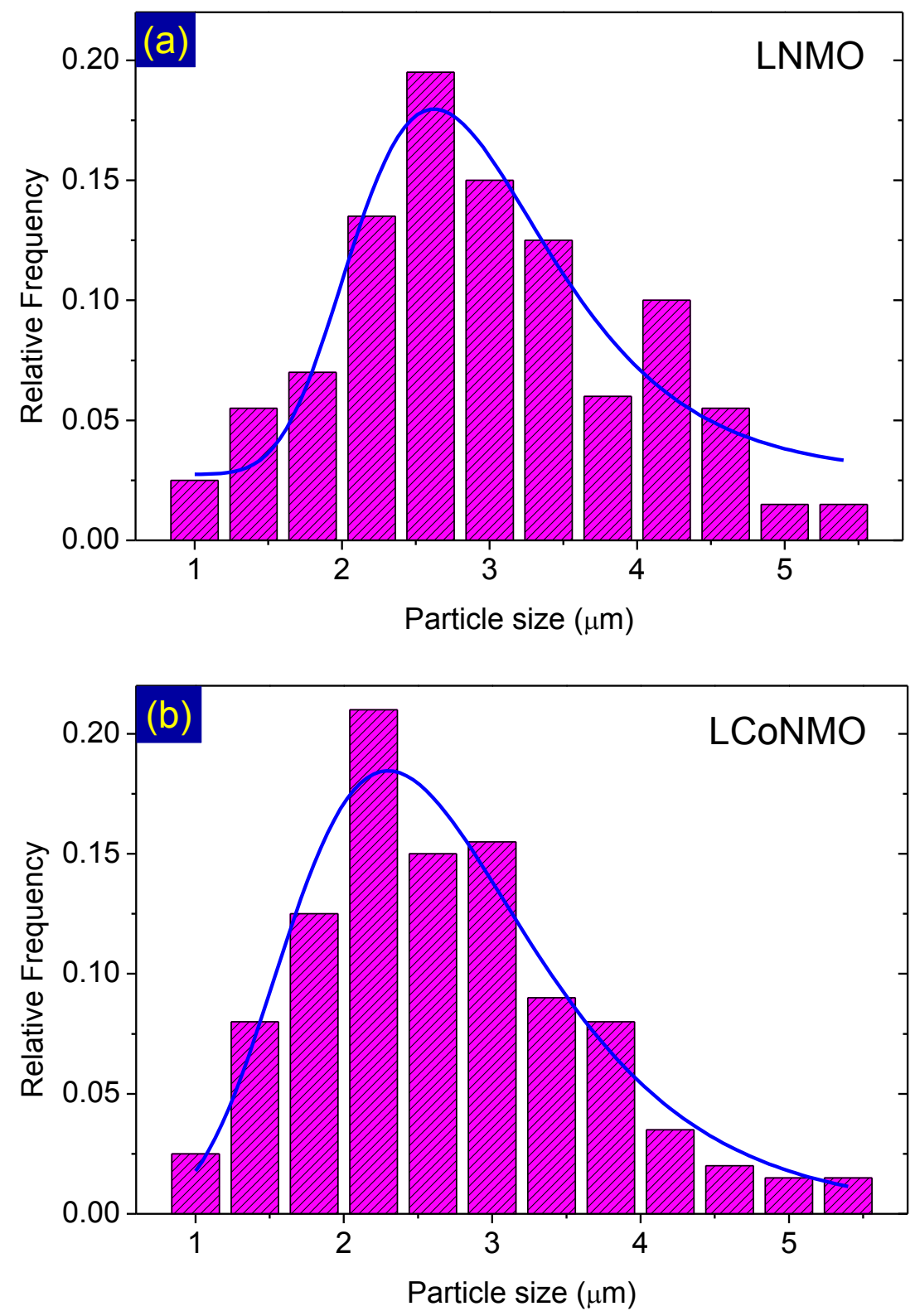

Fig. 2. The Particle size distributions of LNMO and LCoNMO. 


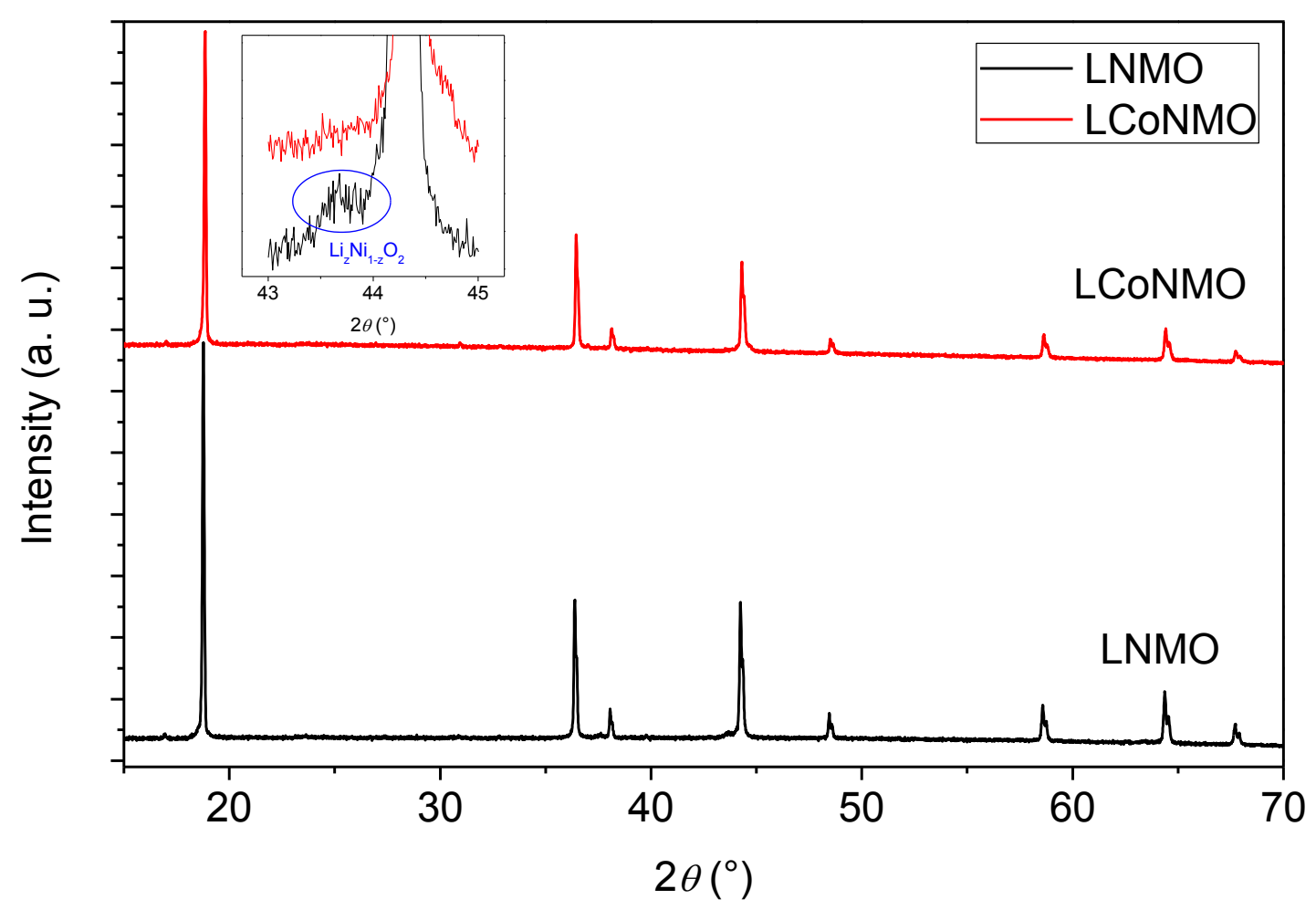

Fig. 3. The XRD patterns of LNMO and LCoNMO. 

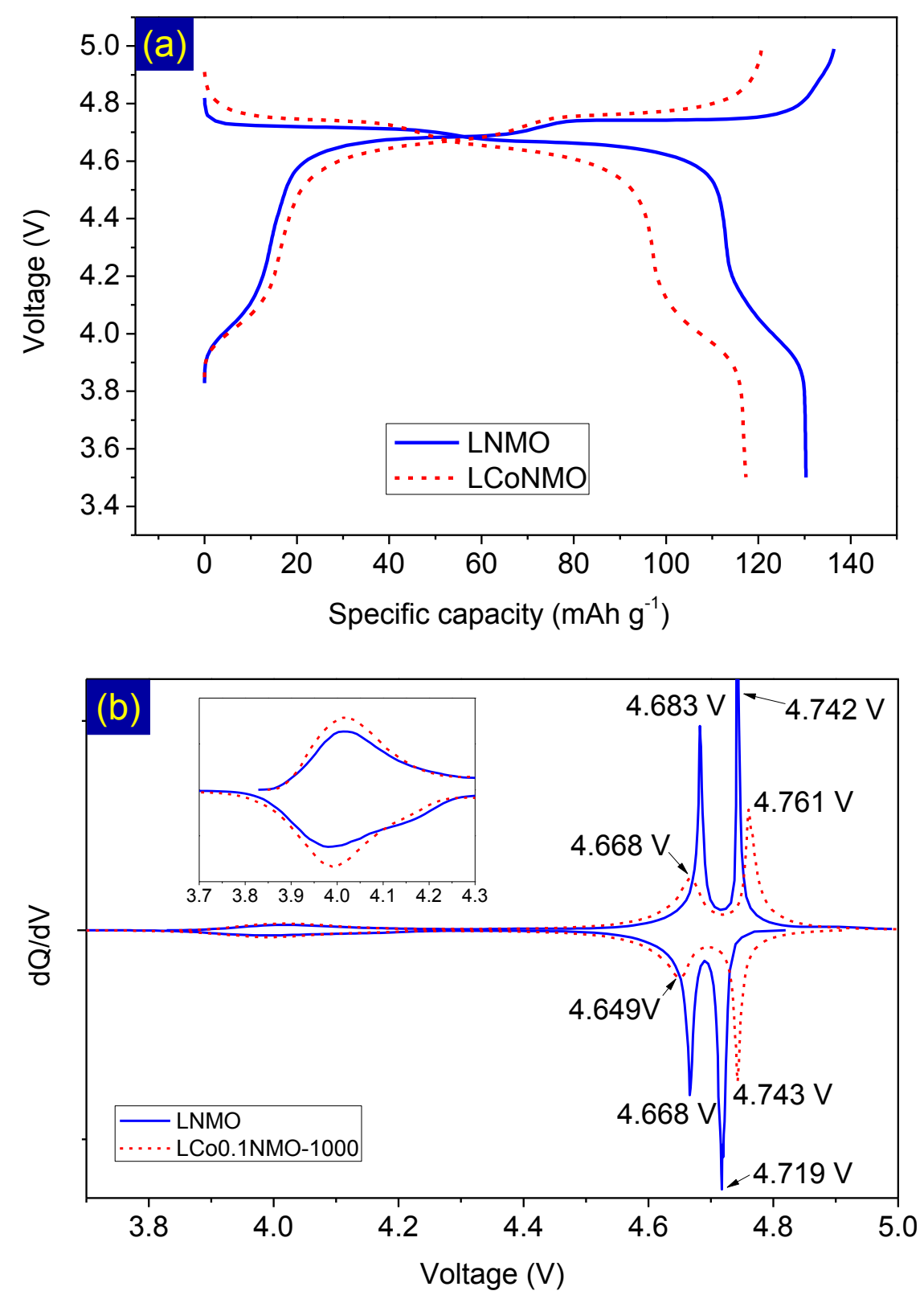

Fig. 4. (a) The charge-discharge profiles and (b) the $d Q / d V$ profiles of LNMO and LCoNMO. The rate is $\mathrm{C} / 5$. 

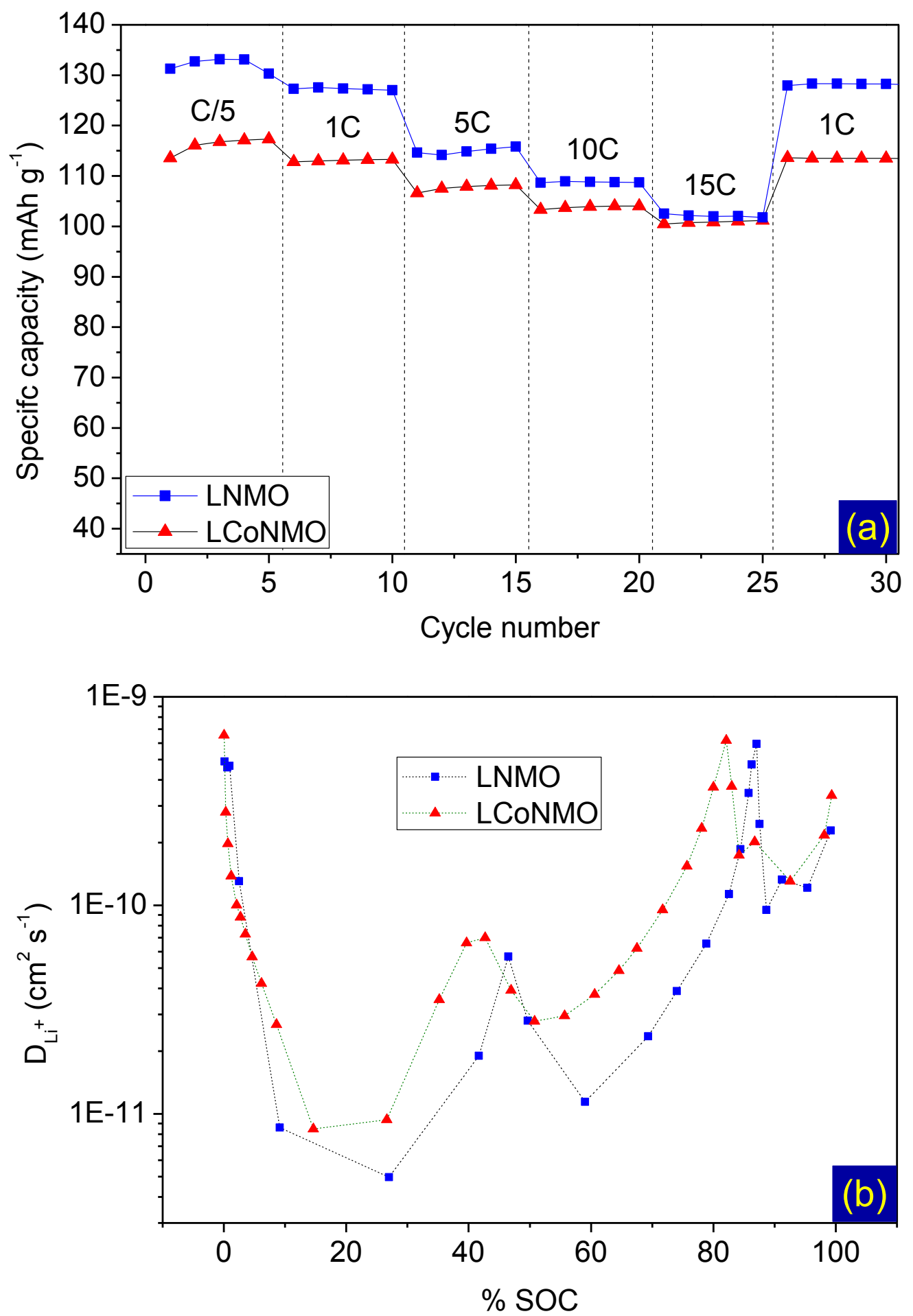

Fig. 5 (a) The specific capacity at different C-rates and (b) chemical diffusion coefficient at different SOC of LNMO and LCoNMO. 
Figure 6
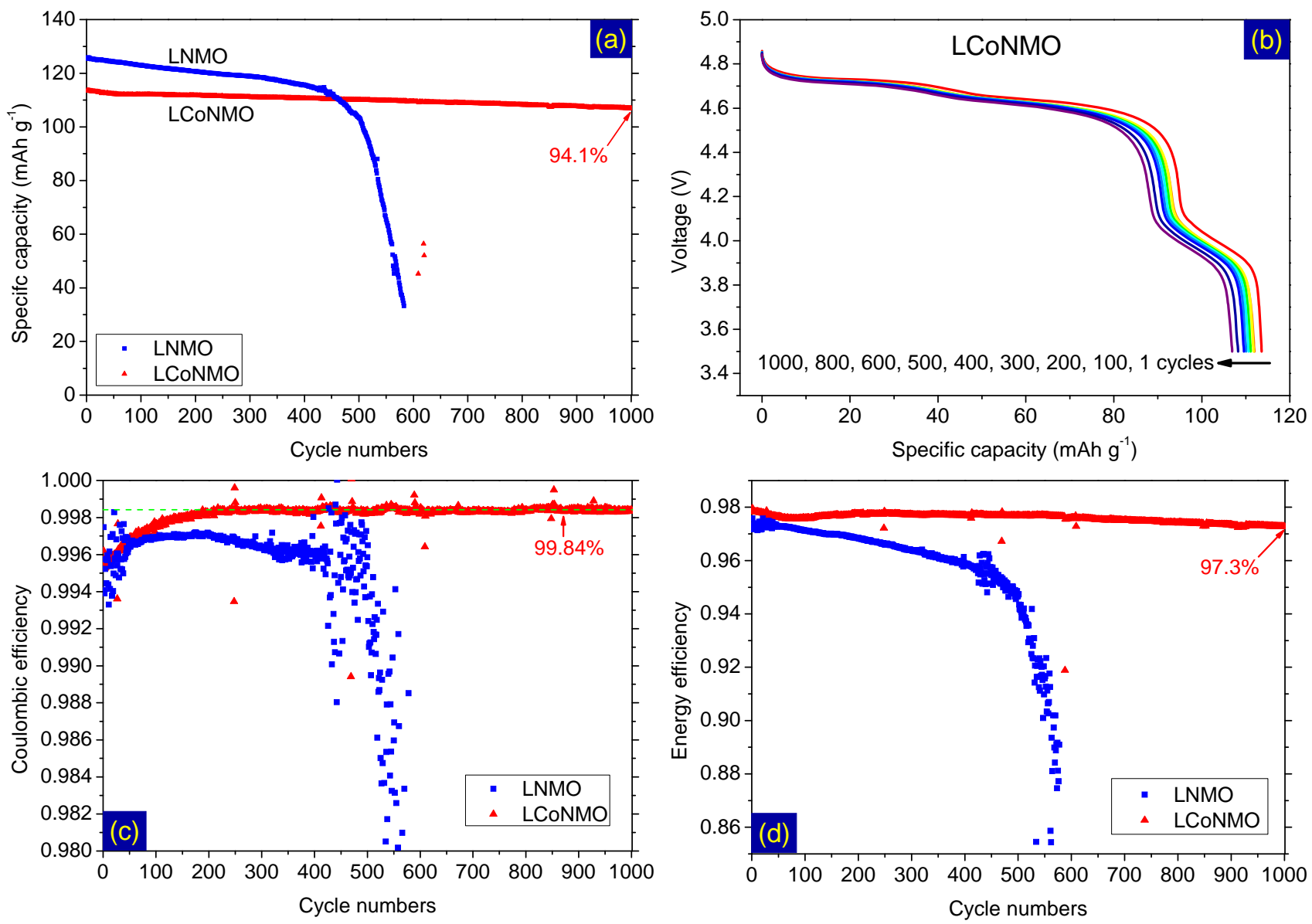